\title{
EFFECTS OF BOTH GARLIC AND ROSEMARY EXTRACTS ON RATS LIVER FIBROSIS : A HISTOCHEMICAL AND IMMUNOHISTOCHEMICAL STUDY
}

\author{
Emaraa M.W.; Ahmed M.I., Refaat W. M.; Mohammed H. L. \\ Pathology Department, Faculty of Medicine, Zagazig University
}

\begin{abstract}
Background: Liver fibrosis is a reversible scarring response that occurs in almost all patients with chronic liver injury.Liver fibrosis may progress to liver cirrhosis, the end-stage liver disease, which has been a globally increasing major health problem with high mortality and morbidity rates in the past twenty years.

Aim: This study aimed at detection of the effects of both Garlic and Rosemary extracts as natural sources on carbon tetrachloride (CCL4) induced rat liver fibrosis.

Materials and methods: This experimental study was carried out on 48 adult male albino rats that were classified into five groups(A-B-C-D-E) each group contain ten rats except group (B)contained eight rats. Group (A) is a control group did not receive any medication, group (B) received Carbon tetrachloride (CCL4) only,group (C) received (CCL4) and Garlic extract,group (D) received (CCL4) and Rosemary extract and group (E) received (CCL4) with both Garlic and Rosemary extracts. This work was carried out during the period from July 2013 to July 2014.

Results: Livers harvested from rats treated with Garlic extract and rats treated with Rosemary extract revealed marked reduction in both the inflammatory reactions and degenerative changes, as well as, reduction of fibrosis. Rats treated with both Garlic and Rosemary extracts revealed mild or niether reduction of inflammation nor fibrosis. microvesicular steatosis was noticed in Rosemary treated group (D).

Conclusion:Both Garlic and rosemary extracts administration with CCL4 significantly ameliorate all necroinflammatory and fibrotic changes in liver tissues when used individually.Thier protective effect was reduced when they were combined together .
\end{abstract}

Key words : Liver, Garlic, Rosemary, cirrhosis, fibrosis.

\section{INTRODUCTION}

C hronic liver disease (CLD) is a significant cause of morbidity and mortality and is, commonly, caused by chronic viral hepatitis B and $\mathrm{C}$, alcoholism and fatty liver disease .The initial stages of CLD are usually asymptomatic such as steatosis or hepatitis. Hepatitis is the inflammation of the liver, resulting in liver cell damage and destruction, while persistence of evidences for continous liver damage for $>6$ months is defined as chronic hepatitis [1] .

Liver fibrosis is a reversible scarring response that occurs in almost all patients with chronic liver injury.Liver fibrosis may progress to liver cirrhosis, the end-stage liver disease, which has been a globally increasing major health problem with high mortality and morbidity rates in the past twenty years [2].

Key morphological features of cirrhosis include diffuse fibrosis, regenerative nodules, altered lobular architecture and establishment of intrahepatic vascular shunts between afferent (portal veins and hepatic arteries) and efferent (hepatic veins) vessels of the liver that represent an essential feature of cirrhosis [3].

The fibrotic response underlies virtually all the complications of end-stage liver disease, including portal hypertension, ascites, encephalopathy, synthetic dysfunction, and impaired metabolic capacity. Theoretically, clinical outcomes or liver-related death should correlate with both the prevalent stage of fibrosis and the rate of fibrosis accumulation over time. In the vast majority of patients with chronic liver injury, fibrosis progresses slowly owing to the remarkable regenerative capacity of the liver [4].

There is a growing expectation that fibrosis can be treated, this offers hope to millions of patients with chronic liver disease worldwide. So it is too important to understand the mechanisms of fibrosis, the impact of genetic polymorphisms on fibrosis progression, and the rising prospects for therapy [5].

Garlic derivatives, possess several hepato protective effects, it have anti-oxidative effects in vitro and attenuates oxidative stresses in vivo [6].

Studies show the effects of administration of rosemary essential oil on the resistance of rat hepatocytes against DNA-damaging oxidative agents proved that it delay and prevents oxidative liver tissue damage. It also acts via inhibiting TGF$\beta 1$ (the most potent cytokine in process of liver fibrosis). So it may give promising effects in treatment of liver disease [7],[8].

\section{MATERIALS AND METHODS}

This work is an experimental study carried out on 48 adult male albino rats their average weight is about 200 gram for each obtained from Faculty of Veterinary Medicine ,Zagazig University and housed in animal house in Faculty of Medicine ,Zagazig University under temperature (20 -2 1 C ) with a 12-h light/12-h dark cycle and had free access to chew and water The experimental procedures were approved by the 
institutional Animal Ethics Committee .This work was carried out during the period from July 2013 to July 2014

\section{Experimental groups :}

- Five experimental groups of adult rats are used and were designed as follows (A,B,C,D,E).

- Each group consisted of ten rats except group (B) contained eight rats

- Group (A) rats are used as control

\section{Animal treatment:}

- Group (A) received ordinary feeding only.

- Group (B) subcutaneously injected by Carbon tetrachloride (CCL4) to induce liver fibrosis twice a week, in a dose of $0.2 \mathrm{ml} / 100 \mathrm{~g}$ in refined olive oil (1:1) for continuous 7 weeks[12].

- Group (C) received subcutaneous injection of (CCL4) in a dose of $0.2 \mathrm{ml} / 100 \mathrm{~g}$ in refined olive oil (1:1) twice a week for continuous 7 weeks in association with daily intraperitoneal administration of garlic extract in a dose of 200 $\mathrm{mg} / \mathrm{kg}$ body weight for continuous 7 weeks [12].

- Group (D) received subcutaneous injection of (CCL4) in a dose of $0.2 \mathrm{ml} / 100 \mathrm{~g}$ in refined olive oil (1:1) twice a week for continuous 7 weeks in association with intra gastric administration of rosemary extract with a dose of $250 \mathrm{mg} / \mathrm{kg}$ body weight for continuous 7 weeks.the dose was calculated as follows(rosmarinic acid,the most important constituent of the plant represents $2 \%$ of the crude extract, the needed dose is 5 $\mathrm{mg}$ [7],so the dose of extract needed is $5 \times 100 / 2=5 \times 50=250 \mathrm{mg}$ of extract which contain $5 \mathrm{mg}$ rosmarinic acid.

- Group (E) received subcutaneous injection of (CCL4) with a dose of $0.2 \mathrm{ml} / 100 \mathrm{~g}$ in refined olive oil (1:1) twice a week for continuous 7 weeks in association with both intraperitoneal Garlic extract and intragastric rosemary extract with the same doses as the previous two groups for continuous 7 weeks.

After 7 weeks animals were sacrified at the same time and their livers were harvested 3 days after the final injection of CC14. After harvesting, livers were divided into two parts, fixed in formalin for histologic and immunohistochemical analysis.

\section{-Preparation of Garlic extract (GE):}

Peeled garlic (500 g) was crushed and transferred in a $1 \mathrm{~L}$ glass bottle and added with an equal volume $(500 \mathrm{~mL})$ of distilled water and the bottle let for $17 \mathrm{~h}$ at room temperature in the dark. The mixture was filtered on a filter paper and the solution collected in 1 litre glass bottle.the extract was stored at $4 \circ \mathrm{C}$ until use $[\mathbf{9 , 1 0}]$.

-Preparation of Rosemary extract (RE):
Dried plant (250g) was crushed and transferred in a 2 Liter glass jar and added with a volume $(1000 \mathrm{ml})$ of ethyl alcohol with a concentration of $70 \%$ and the jar is firmly closed and let for 3-5 days at room temperature with continuous blending of contents twice a day using a wood rod ,after 3-5 days ,the fluid is filtered using a filter paper and the filtrate is evaporated by using the rota-vapour apparatus for 3-4 hours ,alcohol is evaporated and the pure extract is settled in the bottom of the glass bottle, alcohol is added again to the remaining solid material and then evaporated by the same method ,the process is repeated three to four times in order to obtain the whole constituents of the plant. The pure extract obtained was 50 gram diluted in $50 \mathrm{ml}$ water making solution with a concentration of $1000 \mathrm{mg} / \mathrm{ml}$,the extract then is preserved at room temperature until use [11] .

-Masson trichrome staining: all studied cases are stained by Masson trichrome stain,

which is used to detect collagen content and to assess fibrosis score.Collagen fibres appear green .Cytoplasm of hepatocytes appears red.

\section{-Immunohistochemical study:}

Used to identify both transforming growth factor $\beta 1$ (TGF- $\beta 1$ ) and tissue transglutaminase2(tTGSE2).Immunohistochemical reactions were carried out using streptavidin-biotin immunoperoxidase system with primary monoclonal antibodies.Transforming growth factor $\beta 1$ was demonstrated as brownish granules in the cytoplasm of hepatocytes while tissue transglutaminase was demonstrated as brownish staining in the extracellular matrix and perivascular areas

\section{RESULTS}

Inflammatory and degenerative changes as portal tract inflammation, lobular inflammation were present in 8 cases of group B with percentage of $(100 \%)$ of cases ,these findings were reduced significantly in group C involving 2 cases (20\%) and group $\mathrm{D}$ involving 2 cases with portal tract inflammation (20\%) and 3 cases with lobular inflammation (30\%) with appearance of steatosis with group (D) in 6 cases $(60 \%)$.As regarding group $\mathrm{E}$, there was 7 cases $(70 \%)$ having both portal tract inflammation and lobular inflammation, other changes as focal lytic and confluent necrosis were significantly reduced in both groups Cand D.( (Table 1).

Expansion of portal tracts by fibrosis with formation of fibrous septa was the most obvious findings in cases of group B, involving 6 cases (75\%).These findings were totally absent in both groups $\mathrm{C}$ and $\mathrm{D}$ where 7 cases(70\%)of both groups 
had no fibrosis and 3 cases (30\%) revealed only expansion of portal areas with out septa formation.Group $\mathrm{E}$ revealed 6 cases(60\%)with portal fibrous expansion with multiple fibrous bridges formation (Table 2).

All studied cases of group B and 8 cases (80\% )of group $\mathrm{E}$ were positive for TGF- $\beta 1$ while 2 cases $(20 \%)$ of group $C$ were positive for TGF$\beta 1$.All cases of group $\mathrm{D}(100 \%)$ were negative,as well as, control group.This indicates a correlation between the degree of inflammation and fibrosis with TGF- $\beta 1$ immuno-positivity as this cytokine is extremely important in occurrence of liver tissue inflammation and is astrong stimulator for hepatic stellate cells (Table 3 ).

All cases of group $\mathrm{B}(100 \%)$ and 5 cases $(50 \%)$ of group E ,3 cases $(30 \%)$ of group D ,were positive for tTGSE .All cases $(100 \%)$ of group C and control group were negative for tTGSE immunostaining.A correlation was found between fibrosis stage and tTGSE immunostaining positivity indicating that its needed for collagen and other extracellular matrix components for synthesis and stabilization (Table 4).

Table (1): Major histopathological findings (Necro-inflammatory changes) of the studied groups .

\begin{tabular}{|c|c|c|c|c|c|c|c|c|c|c|c|c|}
\hline \multirow[t]{2}{*}{$\begin{array}{c}\text { Histopathological } \\
\text { findings }\end{array}$} & \multicolumn{2}{|c|}{$\begin{array}{c}\text { Group A } \\
\mathbf{N}=\mathbf{1 0}\end{array}$} & \multicolumn{2}{|c|}{$\begin{array}{c}\text { Group B } \\
\mathrm{N}=8\end{array}$} & \multicolumn{2}{|c|}{$\begin{array}{c}\text { Group C } \\
\mathbf{N}=\mathbf{1 0}\end{array}$} & \multicolumn{2}{|c|}{$\begin{array}{c}\text { Group D } \\
\mathbf{N}=\mathbf{1 0}\end{array}$} & \multicolumn{2}{|c|}{$\begin{array}{c}\text { Group } E \\
\mathbf{N}=\mathbf{1 0}\end{array}$} & \multirow[t]{2}{*}{$\mathbf{X}^{2}$} & \multirow[t]{2}{*}{ P value } \\
\hline & $\mathbf{N}$ & $\%$ & $\mathbf{N}$ & $\%$ & $\mathbf{N}$ & $\%$ & $\mathbf{N}$ & $\%$ & $\mathbf{N}$ & $\%$ & & \\
\hline $\begin{array}{l}\text { 1-Portal tract } \\
\text { inflammation }\end{array}$ & 0 & 0.0 & $* 8$ & 100 & 2 & 20 & 2 & 20 & $* 7$ & 70 & 25.8 & $* *<0.001$ \\
\hline $\begin{array}{l}\text { 2-Fatty change } \\
\text { (steatosis) }\end{array}$ & 0 & 0.0 & 7 & 87.5 & 2 & 20 & 6 & 60 & 6 & 60 & 18.4 & $<0.001$ \\
\hline 3-Lobular inflammation & 0 & 0.0 & 8 & 100 & 2 & 20 & 3 & 30 & 7 & 70 & 24.1 & $* *<0.001$ \\
\hline 4-Bile duct proliferation & 0 & 0.0 & 8 & 100 & 2 & 20 & 2 & 20 & 6 & 60 & 24.1 & $* *<0.001$ \\
\hline 5-Interface activity & 0 & 0.0 & 8 & 100 & 2 & 20 & 2 & 20 & 6 & 60 & 24.1 & $* *<0.001$ \\
\hline 6-Focal lytic necrosis & 0 & 0.0 & 8 & 100 & 2 & 20 & 3 & 30 & 6 & 60 & 22.49 & $* *<0.001$ \\
\hline 7-Confluent necrosis & 0 & 0.0 & 8 & 100 & 2 & 20 & 2 & 20 & 7 & 70 & 25.8 & $* *<0.001$ \\
\hline 8-Bridging necrosis & 0 & 0.0 & 6 & 75 & 0 & 0.0 & 0 & 0.0 & 4 & 40 & 24.35 & $* *<0.001$ \\
\hline total & & & & & & & & & & & & \\
\hline
\end{tabular}

Table (2): Fibrotic changes of the studied groups

\begin{tabular}{|c|c|c|c|c|c|c|c|c|c|c|c|c|}
\hline \multirow{2}{*}{$\begin{array}{l}\text { Histopathological } \\
\text { findings }\end{array}$} & \multicolumn{2}{|c|}{ Group A } & \multicolumn{2}{|c|}{ Group B } & \multicolumn{2}{|c|}{ Group C } & \multicolumn{2}{|c|}{ Group D } & \multicolumn{2}{|c|}{ Group E } & \multirow[t]{2}{*}{$X^{2}$} & \multirow[t]{2}{*}{$\mathrm{P}$ value } \\
\hline & $\mathrm{N}$ & $\%$ & $\mathrm{~N}$ & $\%$ & $\mathrm{~N}$ & $\%$ & $\mathrm{~N}$ & $\%$ & $\mathrm{~N}$ & $\%$ & & \\
\hline No fibrosis & 10 & 100 & 0 & 0 & $* * 7$ & 70 & $* * 7$ & 70 & 2 & 20 & 24.64 & $* *<0.001$ \\
\hline $\begin{array}{l}\text { Expansion of portal tracts } \\
\text { with fibrosis with out } \\
\text { fibrous septa }\end{array}$ & 0 & 0.0 & 2 & 25 & 3 & 30 & 3 & 30 & 2 & 20 & 3.74 & 0.44 \\
\hline $\begin{array}{l}\text { Portal expansion with } \\
\text { fibrous septae but without } \\
\text { cirrhosis }\end{array}$ & 0 & 0.0 & $* 6$ & 75 & 0 & 0.0 & 0 & 0.0 & $* 6$ & 60 & 27.2 & $* *<0.001$ \\
\hline $\begin{array}{l}\text { Architecture distortion } \\
\text { with cirrhosis }\end{array}$ & 0 & 0.0 & 0 & 0.0 & 0 & 0.0 & 0 & 0.0 & 0 & 0.0 & 0.0 & 1.0 \\
\hline Total & & & & & & & $\overline{48}$ & & & & & \\
\hline
\end{tabular}


Table (3): The extent of TGF- $\beta 1$ immunostaining in the studied groups:

\begin{tabular}{|c|c|c|c|c|c|c|c|c|c|c|c|c|c|}
\hline \multirow[t]{4}{*}{ Group } & \multirow[t]{4}{*}{ No } & \multicolumn{10}{|c|}{$\begin{array}{c}\text { The extent of TGF-B1 immunoreactivity } \\
\end{array}$} & \multirow{4}{*}{$\mathrm{X}^{2}$} & \multirow{4}{*}{$\mathbf{P}$} \\
\hline & & \multirow{2}{*}{\multicolumn{2}{|c|}{$\begin{array}{c}\text { Negative less } \\
\text { than } 3 \%\end{array}$}} & \multicolumn{8}{|c|}{ Positive } & & \\
\hline & & & & \multicolumn{2}{|c|}{ Total } & \multicolumn{2}{|c|}{$\begin{array}{l}\text { Mild } \\
(3-33)\end{array}$} & \multicolumn{2}{|c|}{$\begin{array}{l}\text { Moderate } \\
(34-60)\end{array}$} & \multicolumn{2}{|c|}{$\begin{array}{l}\text { Marked } \\
\text { (more than } \\
60 \% \text { ) }\end{array}$} & & \\
\hline & & No & $\%$ & No & $\%$ & No & $\%$ & No & $\%$ & No & $\%$ & & \\
\hline Group A & 10 & 10 & 100 & 0 & 0.0 & 0 & 0.0 & 0 & 0.0 & 0 & 0.0 & 7.58 & 0.05 \\
\hline Group B & 8 & 0 & 0 & 8 & 100 & 2 & 25 & 4 & 50 & 2 & 25 & 28.16 & $*<0.001$ \\
\hline Group C & 10 & 8 & 80 & 2 & 20 & 2 & 100 & 0 & 0.0 & 0 & 0.0 & 4.4 & 0.21 \\
\hline Group D & 10 & 10 & 100 & 0 & 0.0 & 0 & 0.0 & 0 & 0.0 & 0 & 0.0 & 7.58 & 0.055 \\
\hline Group E & 10 & 2 & 20 & 8 & 80 & 4 & 50 & 4 & 50 & 0 & 0.0 & 12.43 & $* 0.006$ \\
\hline Total & 48 & 30 & 62.5 & 18 & 37.5 & 8 & 44.4 & 8 & 44.4 & 2 & 11.2 & & \\
\hline
\end{tabular}

Table (4): The extent of tissue transglutaminase immunoreactivity in the studied groups:

\begin{tabular}{|c|c|c|c|c|c|c|c|c|c|c|c|c|c|}
\hline \multirow[t]{4}{*}{ Group } & \multirow[t]{4}{*}{ No } & \multicolumn{12}{|c|}{ The extent of tTGSE immunoreactivity } \\
\hline & & \multirow{2}{*}{\multicolumn{2}{|c|}{$\begin{array}{c}\text { Negative less } \\
\text { than } 3 \%\end{array}$}} & \multicolumn{10}{|c|}{$\begin{array}{r}\text { Positive } \\
\end{array}$} \\
\hline & & & & \multicolumn{2}{|c|}{ Total } & \multicolumn{2}{|c|}{$\begin{array}{l}\text { Mild } \\
(3-33)\end{array}$} & \multicolumn{2}{|c|}{$\begin{array}{c}\text { Moderate } \\
(34-60)\end{array}$} & \multicolumn{2}{|c|}{$\begin{array}{l}\text { Marked } \\
\text { (more than } \\
60 \% \text { ) }\end{array}$} & \multirow[t]{2}{*}{$\mathrm{X}^{2}$} & \multirow[t]{2}{*}{$\mathrm{P}$} \\
\hline & & No & $\%$ & No & $\%$ & No & $\%$ & No & $\%$ & No & $\%$ & & \\
\hline Group A & 10 & 10 & 100 & 0 & 0.0 & 0 & 0.0 & 0 & 0.0 & 0 & 0.0 & 6.32 & 0.09 \\
\hline Group B & 8 & 0 & 0 & 8 & 100 & 2 & 25 & 2 & 25 & 4 & 50 & 30.0 & $* *<0.001$ \\
\hline Group C & 10 & 10 & 100 & 0 & 0.0 & 0 & 0.0 & 0 & 0.0 & 0 & 0.0 & 6.32 & 0.09 \\
\hline Group D & 10 & 7 & 70 & 3 & 30 & 3 & 100 & 0 & 0.0 & 0 & 0.0 & 6.32 & 0.09 \\
\hline Group E & 10 & 5 & 50 & 5 & 50 & 3 & 60 & 2 & 40 & 0 & 0.0 & 3.28 & 0.34 \\
\hline Total & 48 & 32 & 66.7 & 16 & 50 & 8 & 50 & 4 & 25 & 4 & 25 & & \\
\hline
\end{tabular}

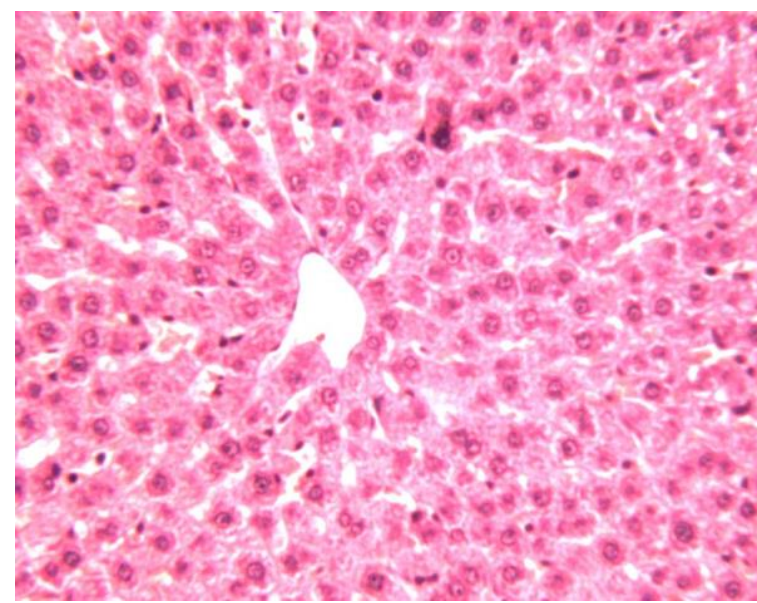

(A)

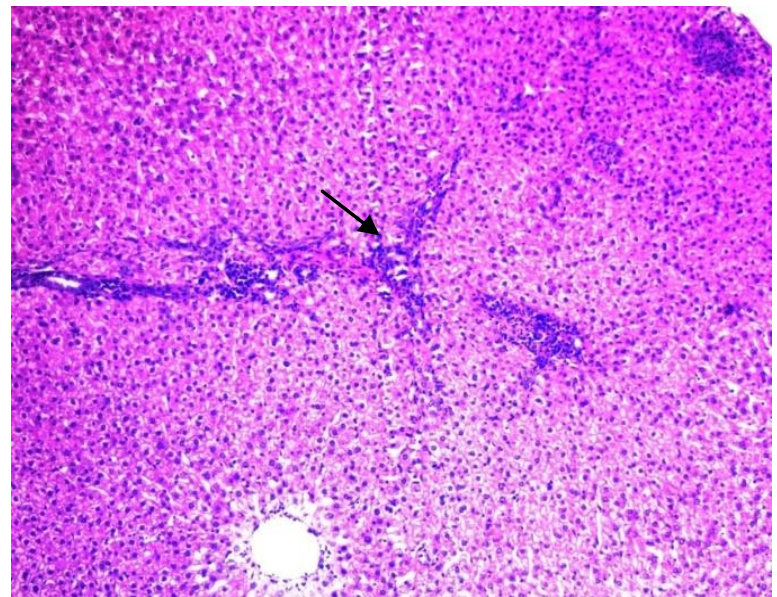

(B) 


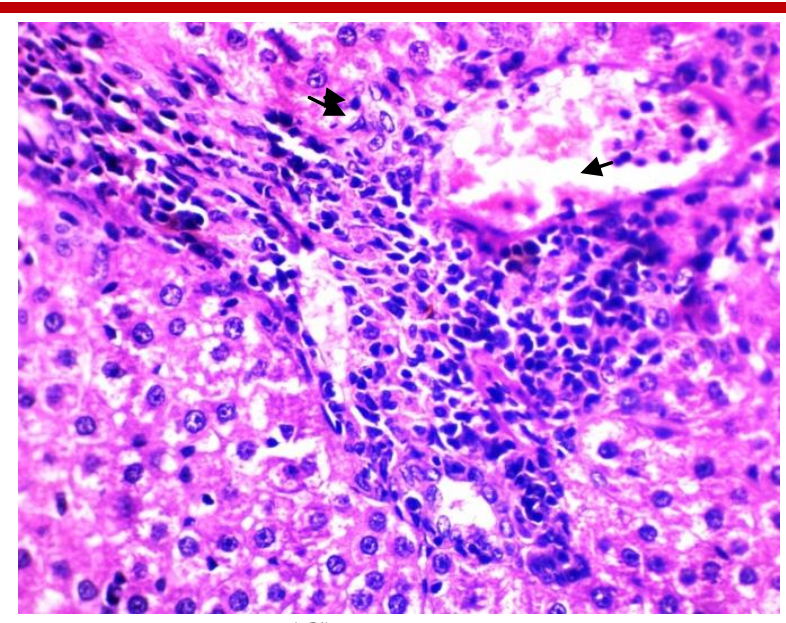

(C)

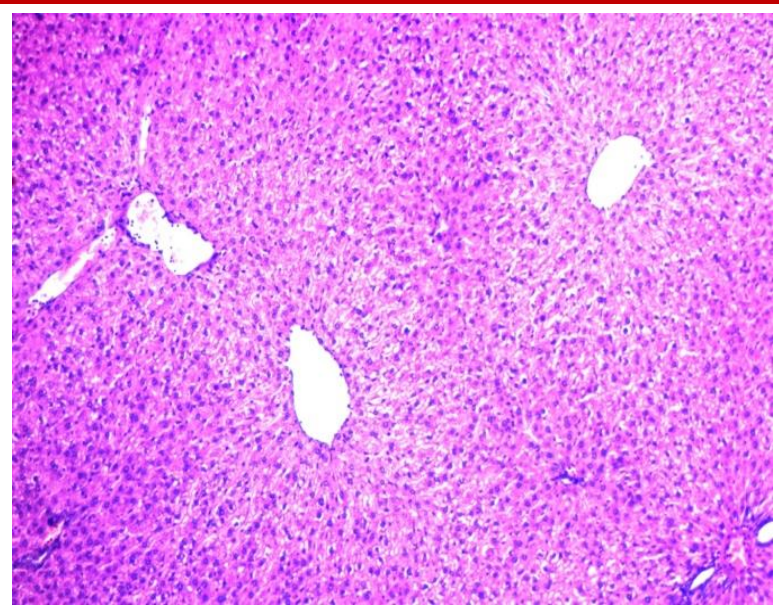

(D)

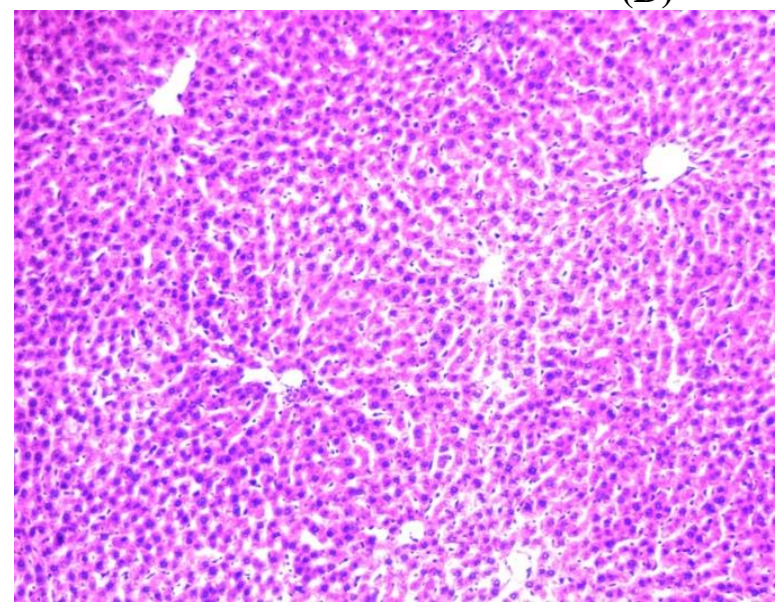

(E)

Fig. (1): (A) Section of rat liver of group A show normal architecture of hepatocytes radiating from central vein(H\&Ex200). (B) Liver section of group B showing bridging necrosis, infiltrated by mononuclear cells and connecting two structures, foci of confluent necrosis also seen.(H\&Ex100) (C) Section of group B show marked interface hepatitis and portal tract infiltration by mononuclear cells(H\&Ex200). (D) Section from group D showing normal hepatic lobulation and absence of portal tract inflammation(H\&Ex100) (E) Section from group $\mathrm{C}$ showing normal hepatic lobulation and absence of portal tract inflammation.(H\&Ex100).

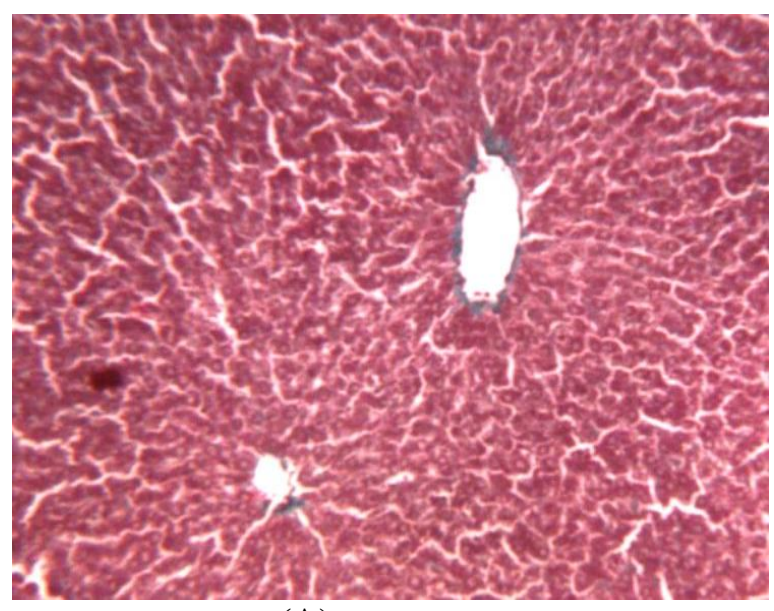

(A)

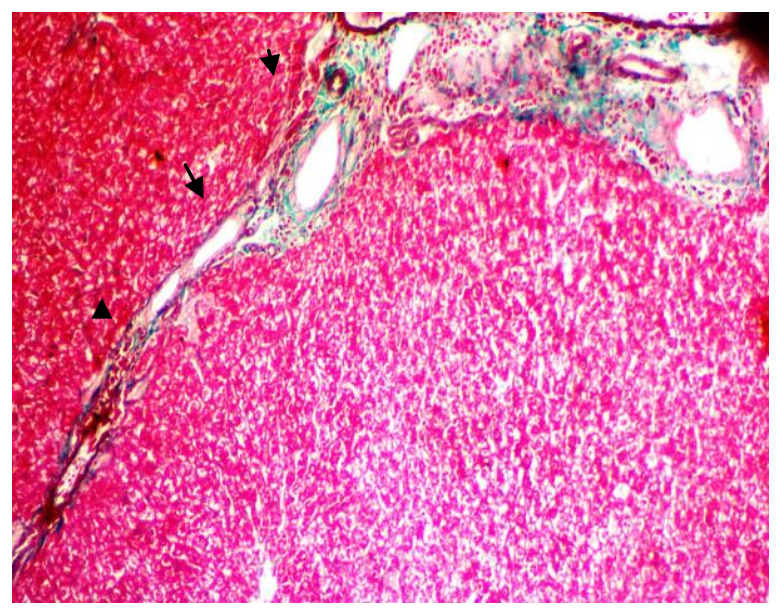

(B) 


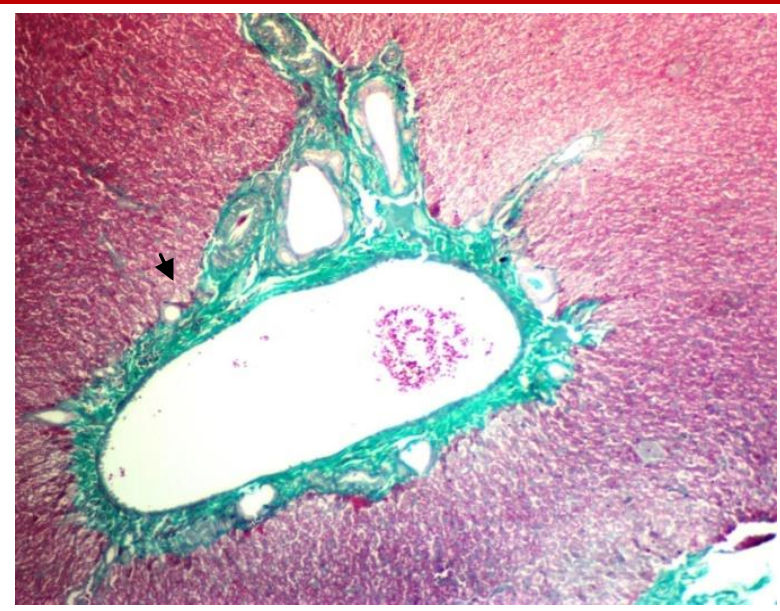

(C)

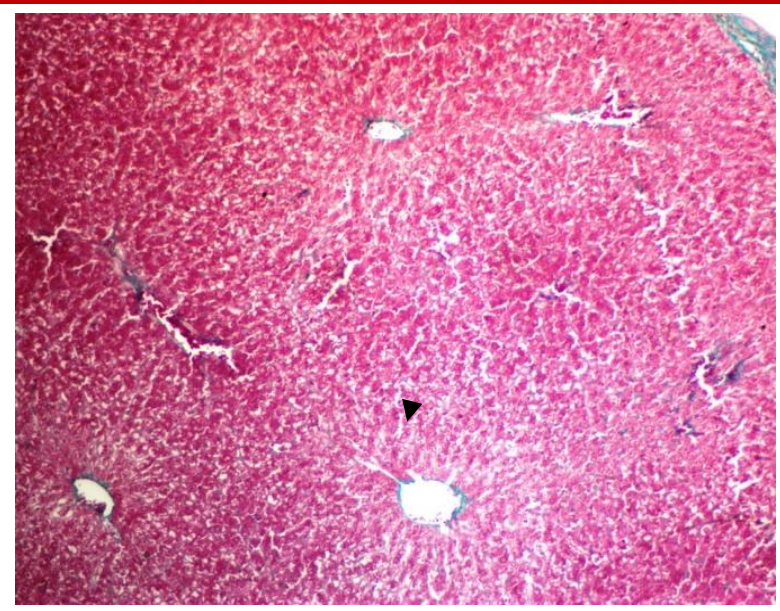

(D)

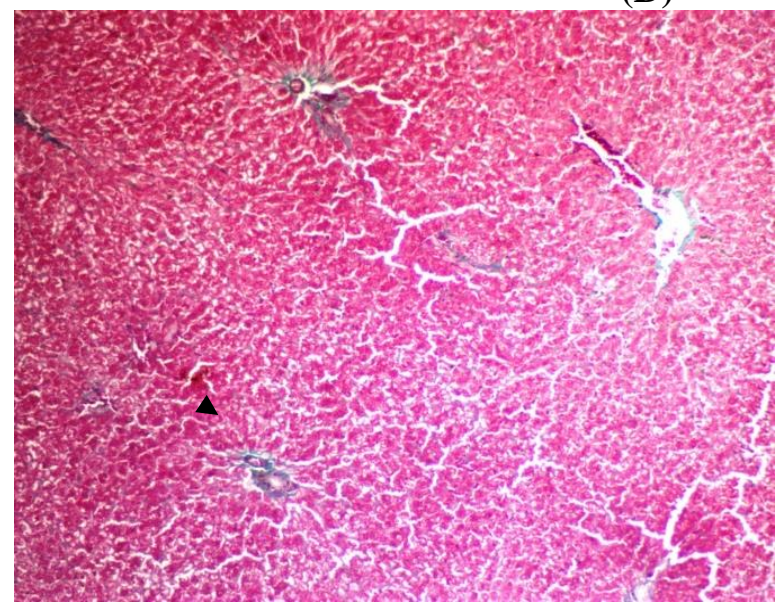

(E)

Fig. (2): (A) Section of rat liver of group A showing within normal hepatic lobules and absence of fibrosis in portal tracts (Masson trichrome stain x200). (B) Liver section of group B showing presence of multiple fibrous bridges connecting porto-portal and porto-central areas.((M.Tx100). (C) Show liver tissue section of group B showing widely dilated portal tracts that expanded by fibrosis and giving short fibrous septa.(M.Tx100). (D) and (E) Show section of group C and D respectively showing within normal portal tracts without significant fibrosis or fibrous bridging.( (M.Tx100).

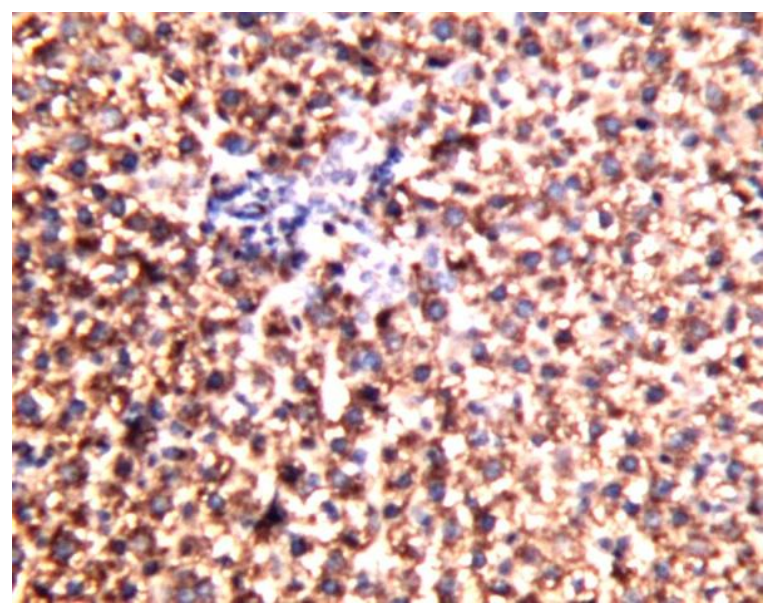

(A)

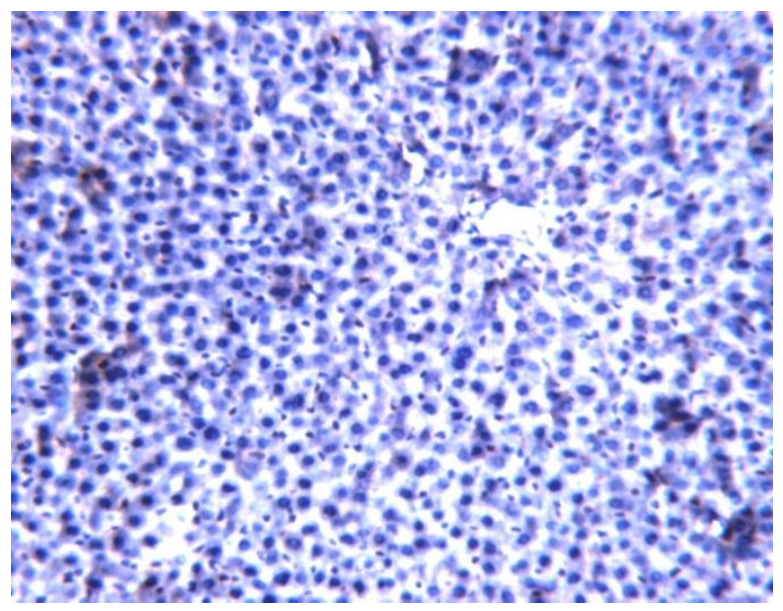

(B) 


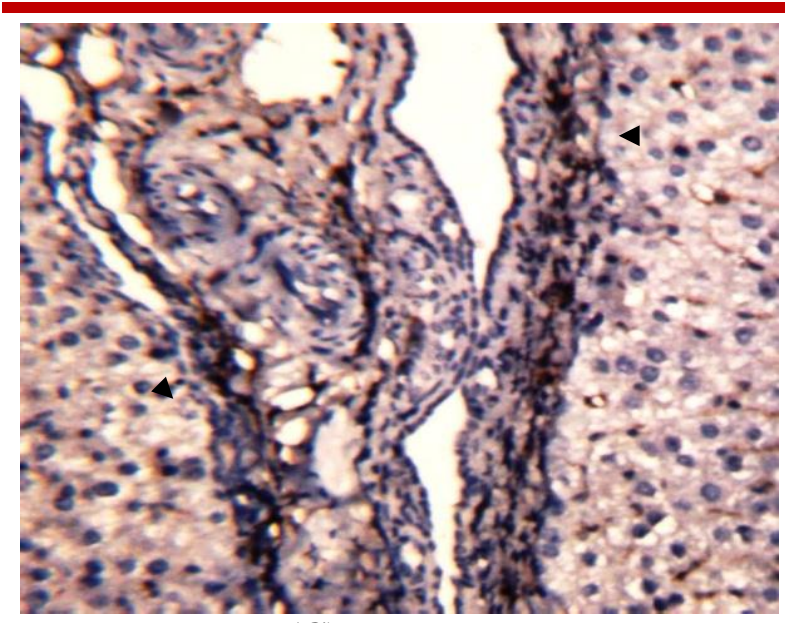

(C)

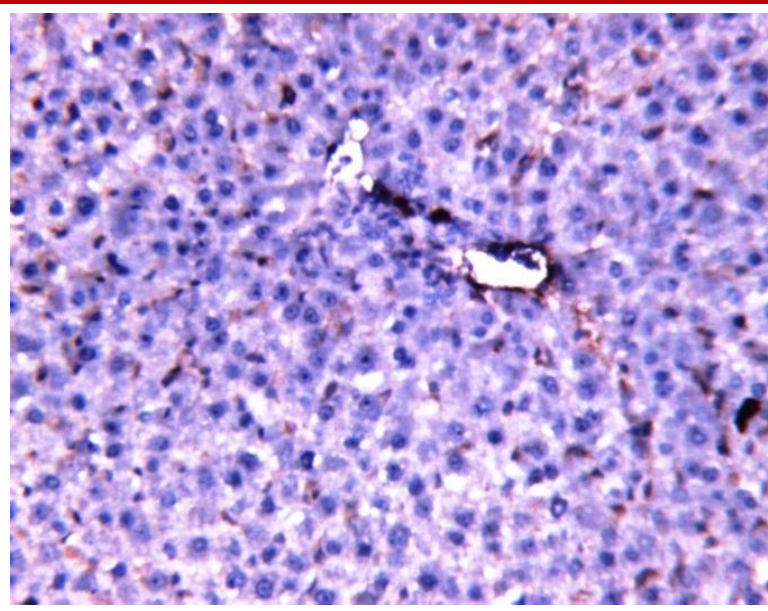

(D)

Fig.(3):(A) A case of group B showing strong TGF- $\beta 1$ cytoplasmic positivity.( TGF- $\beta 1$, Mayers hematoxylin counter stain $\mathrm{x} 200$ ). (B) A case of group D showing negative cytoplasmic immunoreaction for TGF- $\beta 1$ (TGF- $\beta 1$, Mayers hematoxylin counter stain x200). (C) A case of group B showing ECM positive immunoreaction for TGSE in portal tract (TGSE, Mayers hematoxylin counter stain x200). (D A case of group C showing negative immunoreaction for TGSE (TGSE, Mayers hematoxylin counter stain x200).

\section{DISCUSSION}

The main findings in this study, were presence of a wide range of inflammatory and degenerative changes with significant differences between the group which submitted to $\mathrm{CCl} 4$ only and the other groups that have been treated with garlic andlor rosemary extracts. Garlic and rosemary treated groups showed a significant decrease in necro-inflammatory changes as portal tract inflammation and lobular inflammation had been significantly decreased. Necro-inflammatory changes had not been significantly changed in group (E) that received both extracts at the same time. It may be explained by the presence of drug interaction between both Garlic and Rosemary extracts.

Group B that received CCL4 for 7 weeks showed a significant increase in necroinflammatory changes throughout the hepatic lobule with a predominance of portal tract inflammation, focal lytic necrosis, confluent necrosis, interface hepatitis ,as well as, marked central veins and sinusoidal congestion .These findings are near to the findings of Giuseppe et al. [12]

It was found that $\mathrm{CCl} 4$ administration in rats resulted in liver injury in the form of hepatocyte necrosis and degeneration, as well as, infiltration of inflammatory cells in the form of portal tract inflammation and lobular inflammation, which go with the results of Eun et al [13] and Jia et al. [6].

The results of our study revealed that livers harvested from rats treated with Garlic extract (group C) revealed a regular morphology of liver parenchyma that showed intact hepatocytes, sinusoids and normal organization of hepatic cords with a significant reduction of inflammatory and degenerative changes. There were a reduction in portal tract inflammation, interface hepatitis, mild focal lytic and absent confluent necrosis, as well as, decreased bile duct proliferation as compared with the model group rats, which was compatible with the results of Nursal et al. [14] who studied the role of long-term administration of aqueous garlic extract (AGE) and its effect to alleviate oxidative damage and liver inflammation in rats after induction of inflammation via Bile duct ligation .

Our results also showed that GE administration with CCL4 significantly ameliorate all necro-inflammatory and degenerative changes that occurred in liver tissues compared with the group that received CCL4 alone. These findings go with that reported by Giuseppe et al. [12].

This effect of GE may be explained by the presence of the organosulfer compound $\mathrm{S}$ allylmercaptocysteine (SAMC) which had antioxidant effects on mice that exposed to hepatotoxicity by CCL4 administration. These findings was explained by Jia et al. [6].

Organosulfur components present in garlic promote the induction of glutathione Stransferases. the agents may provide the sulfur source required for the synthesis of GSH . Thus, the organosulfurs increase antioxidant activities by enhancing homeostatic regulation of cellular GSH contents as well as by promoting detoxification of metabolic intermediates through induction of phase II metabolizing enzymes which was reported by Kim et al. [15]. 
Garlic (Allium sativum) was selected as a potential natural source of organosulphur compounds, which are a group of phytochemicals characterized by antioxidant properties. So it has a protective antioxidant effects on liver tissue.[12]

According to our results, livers harvested from rats treated with Rosemary extract (group D) revealed that the inflammatory reactions and degenerative changes were obviously reduced, there were a reduction in portal tract inflammation, interface hepatitis, mild focal lytic and absent confluent necrosis. These findings are nearly similar to that reported by Amin and Hamza [16] who studied hepatoprotective effects of crude water extracts of Rosemary against drug-induced oxidative stress and hepatotoxicity in rats which was induced by Azathioprene (AZP).

Results of the present study revealed that, the extract of RO had hepatoprotective effects against CCL4 -induced liver damage and to prevent Histopathological changes induced by CCL4.These findings coincided with that stated by Hoefler et al. [17]

Haraguchi et al [18] and Fahim et al. [19] attributed these effects to the presence of high percentages of antioxidant compounds in $\mathrm{RO}$ extract. It has been shown that RO extract and its antioxidant compounds inhibit lipid peroxidation and free radicals generations in vitro and in vivo.

Rosmarinic acid, carnosic acid, carnosol, rosmanol, epirosmanol, carotenoid and alphatocopherol, have been documented as the principal antioxidant constituents of RO extracts [20].

Naciye et al.[21] studied the antioxidant components in rosemary extract .It was found to contain carnosic acid, rosmarinic acid in addition to alpha tocopherol it may also contain some other antioxidant components.

In the present study, it was found that harvested livers from rats treated with both Garlic and Rosemary extracts (group E) revealed a slight or no improvement of inflammatory and degenerative changes. There were slight reduction in portal tract inflammation ,interface hepatitis, focal lytic and confluent necrosis. This finding may be explained by the presence of interaction between both Garlic and Rosemary extracts. This probable interaction resulted in ablation of their hepatoprotective effect when they are used in combination, while this effect was obvious when they are used individually.

Up to our knowledge, there is no experimental studies investigating hepatoprotective effects of both agents (Garlic extract \&Rosemary extract) together.This point needs further investigations in subsequent experimental studies.

According to our results, Massson trichrome staining of livers harvested from rats treated with $\mathrm{CCl} 4$ for 7 weeks showed a pattern of fibrosis with established fibrous septa linking hepatic central veins and further new matrix bridging these areas to the portal tracts. These findings are close to that of Giuseppe et al. [12].

Our results also revealed the presence of fibrous tissues extending into hepatic lobules which come with that of Gui et al. [7].

Results of the present study revealed that, Masson trichrome staining of (group C) showed presence of mild or no portal fibrosis: there were no bridging fibrous septa from the hepatic veins to the portal tracts. There were portal areas without fibrous expansion or septa. In addition, the caliber of the remaining septa in other areas was reduced in width.There was a highly significant reduction of fibrosis in group $\mathrm{C}$ confirming the role of Garlic extract in preventing $\mathrm{CCl} 4$ induced liver fibrosis in rats. These results are close to that of Giuseppe et al. [12].

Our results are nearly similar to that of Nursal et al. [14] who found that long-term administration of aqueous garlic extract alleviate liver fibrosis and oxidative damage induced by biliary obstruction in rats.They found a significant reduction in hepatic collagen content of the liver which revealed a regular morphology of parenchyma with intact hepatocytes and sinusoids and normal architecture. They also assessed that AGE treatment reduced the production of free radicals to the control level.

Mild or no portal fibrosis found in group (D) using Masson trichrome staining .There were no bridging septa from the hepatic central veins to the portal tracts with highly significant reduction of fibrosis

Massson trichrome staining of livers from group (E) showed a pattern of fibrosis with established septa linking hepatic central veins and further new matrix bridging these areas to the portal tracts.Up to our knowledge ,there is no experimental studies investigating antifibrotic effects of both agents (Garlic \&Rosemary extract) together to compare with our results.

According to the present study, a significant correlation was noticed between grade of necroinflammation and stage of fibrosis according to METAVIR scoring system ,All cases of mild activity showed stage 1 fibrosis and all cases with severe activity presented with F3 stage.

These results agreed with Martinelli et al. [22] and Sandulescu et al. [23]. They reported that 
necroinflammatory scores were linked to the development of fibrosis. These data may suggest the roles played by inflammatory mediators in initiation and progression of fibrosis through activation of HSCs. On the other hand, our results were not identical to the reports of Tomanovic et al. [24] who found no correlation existing between necro-inflammatory activity and the stage of fibrosis.

In this study, steatosis appeared as fat droplets within hepatocytes, distributed haphazardly within the lobules as microvesicular steatosis. It was moderate in groups B and D, mild in groups $\mathrm{C}$ and $\mathrm{E}$.

Steatosis was highly significantly absent in groups $\mathrm{C}$ and $\mathrm{A}$. steatosis was significantly high in group D.

Our findings was contradicted with Gui et al. [7] who studied the anti fibrotic effects of Rosmarinic acid (RA) (which is a component of Rosemary extract) on rats after CCL4 administration .They found no significant steatosis in the group which received refind Rosmarinic acid.This may be attributed to over dosage or to the use of the crude alcoholic extract of rosemary or small sample size in our study.

In the present study,it was found that all cases of CCL4 group were positive for TGF- $\beta 1$, group C showed mild positivity, while the control group and RO group cases were negative. Both extent and intensity of immunoreactivity of TGF- $\beta 1$ was significantly high in groups $\mathrm{B}$ and $\mathrm{E}$.

These results are in accordance with that of Gui et al. [7] who found that expression of TGF- $\beta 1$ in the CCL4 group was significantly increased.

According to results of our study, it was found that, there was a high significant reduction in both the extent and intensity of TGF- $\beta 1$ immunoreactivity in RO treated group. All cases that were treated with $\mathrm{RO}$ showed negative immunoreactivity for TGF- $\beta 1$.

This previous result in agree with results of Gui et al. [7] who investigated immunohistochemical detection for liver TGF- $\beta 1$ after administration of Rosimarinic acid (a constituent of RO) .It showed that expression of TGF- $\beta 1$ was significantly reduced .They also stated that ,the hepatoprotective role of RO extract is attributed not only to its antioxidant properties, but also via its inhibitory effect on the master cytokine of fibrosis (TGF- $\beta 1$ ) clarifying the propable role of this natural plant in preventing liver fibrosis .

In the present study we found that ,the distribution of tTGSE in the fibrotic liver in cases that received CCL4 only have shown that tTGSE is immunolocalised with collagen fibres indicating that tTGSE is mainly found in the ECM of damaged liver.Our results showed that the extent and intensity of tTGSE expression was significantly high in group $\mathrm{B}$ and it was significantly reduced in group $\mathrm{C}$ which provided further insight into the role of tTGSE in fibrosis, showing that the enzyme localization in damaged liver tissue acquires structural morphologies quite similar to that obtained by collagen deposition. Both tTGSE and collagen staining were strongly reduced by GE treatment.

The anti-fibrotic effects of garlic, GEs and some garlic constituents in different models of liver damage have been demonstrated by their antioxidant activity. This also was explained in this study, where the antifibrotic role of GE may be occurred by its inhibitory effect on tTGSE enzyme which is involved in extracellular matrix stabilization.

Our results respecting the anti-fibrotic effects of GE were explained previously by Giuseppe et al. [12]. They stated that the prevention of liver injury by GE may be correlated to the direct inhibition of TGSE activity that in turn, reduces the levels of enzyme gene expression and transduction, possibly through a mechanism of negative feedback.

They also added that, it is known that in liver tissue TGF- $\beta 1$ stimulates the hepatic stellate cell differentiation into myofibroblasts that release collagen into the ECM where it is cross-linked by tTGSE. Furthermore, tTGSE activates latent TGFb1, leading to de novo synthesis of tTGSE in a selfmaintaining system. Data obtained from this study allows us to hypothesise that this mechanism, which leads to the formation of fibrosis, can be inhibited by garlic through the blockage of tTGSE activity and expression.

In the present study we suggested that the effect of the organosulfur compounds found in garlic not only via its antioxidant properties, but also, through its effect on the tissue transglutaminase enzyme involved in collagen synthesis leading to reduction of the fibrosis stage in CCl4-induced hepatotoxicity, which may shed some light on the prevention of liver damage by taking garlic extract as a supplement in the daily diet.

A significant correlation was found between both extent and intensity ofTGSE immunoreactivity and METAVIR score of necroinflammatory grade and also fibrosis stage, where negative expression of TGSE is highly significant in stage F0 while positive TGSE2 expression was highly significant in both stages of F2 and F3. 
The results of the present study disagreed with that of Yury et al [25]who studied fibrosis progression and its spontaneous regression after advanced liver fibrosis was induced by carbon tetrachloride in TGSE2 difficient mice and their wild-type littermates to study for up to 36 weeks. They found that Transglutaminase activity was increased in fibrosis, and the level of TG2 messenger RNA correlated with the expression of fibrosis-related genes. Bio-chemical analysis revealed progressive collagen stabilization in TGSE 2 difficient mice, TGSE activity are upregulated during hepatic fibrosis progression, but do not contribute to fibrogenesis or stabilization of the collagen matrix. TGSE2 deletion does not promote regression of liver fibrosis and independent collagen cross-linking is a remarkable feature of progressing hepatic fibrosis

These results are contraversed by results of our study and this difference may be attributed to our small sample size or the long interval of their study 36 weeks, while our study lasted 7 weeks.

\section{REFERENCES}

1- Allan R.; Thoirs K. and Phillips M. (2010): Accuracy of ultrasound to identify chronic liver disease.World J. Gastroenterol.; 28(16):35103520

2- Jonel T.; Evrim A.; Natalia E.; Ingo S., et al. (2012): Hepatic and serum levels of miR-122 after chronic HCV-induced fibrosis J.Hepatol.; 1: 110-115.

3- Massimo P.; Matteo R. and Michele Z. (2011): Liver cirrhosis. J.Best Pract. \& Resear.Clin. Gastroenterol.; 25: 281-290.

4- Ju-Hee, L.; Hyunseung, L.; Yoon- ki J.; Kyunghee, J.; et al. (2011): The Use Of Low Molecular weight Heparine-Pluronic Nanogels To Impede Liver Fibrosis By Inhibition The TGF- $\beta /$ SMAD Signaling Pathway. J.Biomat. ;(32):1438-1445.

5- Scott L. (2008): Hepatic fibrosis-Overview. J.Toxicol.; 254: 120-129.

6- Jia X.; Emily C.; Liong M.;Yick-P. et al. (2012): S-allylmercaptocysteine reduces carbon tetrachloride-induced hepatic oxidative stress and necroinflammation via nuclear factor kappa Bdependent pathways in mice. Eur. J. Nutr.; 51: 323-333.

7- Gui L.; Wang J.; Jing T.; Gui W.; et al. (2010): In Vivo And In Vitro Effects Of Rosemarinic Acid On Experimental Liver Fibrosis.J.phytomid.; 17: $282-288$

8- Eva H.; Darina S. and Jana N. (2010): Administration of rosemary essential oil enhances resistance of rat hepatocytes against DNA-damaging oxidative agents. J.Food Chem. ;123: 151-156.

9- BatVrel, H.F.; Aktan, S.; Aykut, C.; Yeg־en, B.C. et al. (1996): The effect of aqueous garlic extract on the levels of arachidonic acid metabolites (leukotriene $\mathrm{C} 4$ and prostoglandin E2) in rat forebrain after ischemia-reperfusion injury. Prostaglandins Leukot. J.Essen.Fatty Acids.; 54: 289-292.

10-Sener, G.; Sat Vroglu, H.; Sehirli, A.O. and Kacmaz, A. (2003): Protective effect of aqueous garlic extract against oxidative organ damage in a rat model of thermal injury. J.Life Sci.; 73: 81-91

11-Botsoglou N.; Taitzogloub I.; Zervos E.; Botsoglou M., et al. (2010):Potential of long-term dietary administration of rosemary in improving the antioxidant status of rat tissues following carbon tetrachloride intoxication. J.Food and Chemic Toxicol.; 48 : 944-950

12-Giuseppe A.; Daniela C.; Giovanna M.; Paola V., et al. (2010): Garlic Extract Prevents CCL4 Induced Liver Fibrosis In Rats: The Role of Tissue Transglutaminase. J.Diges. and Liver Dis.; 42:571-577.

13-Eun Y.;Sung H.; Myong S.; Choon W., et al. (2005): Garlic oil and DDB, comprised in a pharmaceutical composition for the treatment of patients with viral hepatitis, prevents acute liver injuries potentiated by glutathione deficiency in rats.J. Chemico-Biolog. Interac.t; 155 :82-96.

14-Nursal G.; Levent K.; O"zer X.; Feriha E., et al. (2005): Long-term administratio $\mathrm{n}$ of aqueous garlic extract (AGE) alleviates liver fibrosis and oxidative damage induced by biliary obstruction in rats J.Life Sci.; 76: $2593-2606$. .

15-Kim S.; Chung H. and Cho J. (1996): Molecular mechanism for alkyl sulfide-modulated carbon tetrachloride-induced hepato-toxicity: The role of cytochrome P450 2E1, P450 2B and glutathione S-transferase expression, J. Pharmacol. Exp. Ther; 277 : 1058-1066.

16-Amin A. and Hamza A. (2005): Hepatopro tective effects of Hibiscus, Rosmarinus and Salvia on azathioprine-induced toxicity in rats.J.Life Sci.;77 : $266-278$

17-Hoefler, C.; Fleurentin, J.;Mortier, F.; Pelt J. M. and Guillemain J. (1987): Comparative choleretic and hepatoprotective properties of young sprouts and total plant extracts of Rosmarinus officinalis in rats. J.of Ethnopharm.; 19:133-143.

18-Haraguchi, H.;Saito, T.; Okamura, N. and Yagi, A. (1995): Inhibition of lipid peroxidation and superoxide generation by diterpenoids from Rosemarinus officinalis. J.Plan. .Medica.; 61: 333-336.

19-Fahim, F. A.; Esmat, A. Y.; Fadel, H. M.; \& Hassan, K.F. (1999): Allied studies on the effect of Rosmarinus officinatis L. on experimental hepatotoxicity and mutagenesis. Intern. J.of Food Scien. and Nutr.; 50: 413-427.

20-Munne-Bosch, S.; Schwarz, K.and Alegre, L. (1999): Enhanced Formation of alpha-tecopherol and highly oxidized abietane diterpenes in waterstressed rosemary plants. Plan. Physiol.; 121: 1047-1052.

21-Naciye E.; Guler A.and Erol A. (2008): Antioxidant activities of rosemary (Rosmarinus 
Officinalis L.) extract, blackseed (Nigella sativa L.) essential oil, carnosic acid, rosmarinic acid and sesamol .J.Food Chem.; 110: 76-82.

22-Martinelli A.; Ramalho L. and Zucoloto S. (2004): Hepatic stellate cells in hepatitis patients: Relationship with liver iron deposits and severity of liver disease. J.Gastroenterol.; 12(30): 48974901.

23-Sandulescu L.; Rogoveanu I.; Ciurea T., et al. (2011): Immunohistochemical study of stellate cells in patients with chronic viral hepatitis C genotype 1.Rom. J. Morpho, Embryol.; 52:137143.

24-Tomanovic N.; Boricic I.; Dimitrije C., et al. (2009): Activated liver stellate cells in chronic viral hepatitis C: Histopathologic \& Immunohistochemica study. J. Gastrointes. Liver Dis.; 18(2): 163-167.

25-Yury P.; Deanna Y.; Sverdlov A.; Sharma K., et al. (2011): Tissue Transglutaminase Does Not Affect Fibrotic Matrix Stability or Regression of Liver Fibrosis in Mice. J.Gastrointrol.; 140:1642-1652. 